\title{
Effect of Transition Curvature on Signal Quality for Narrow Track Recording
}

\author{
M. Shiimoto, H. Katada, Y. Urakami, M. Hashimoto, M. Sugiyama, T. Ichihara, and K. Nakamoto
}

Central Research Laboratory, Hitachi Ltd., 2880 Kozu, Odawara, Kanagawa 256-8510, Japan

\begin{abstract}
We investigated the effect of transition curvature on track edge noise through experiments and calculations. We measured and calculated two types of recording heads that had similar magnetic write widths, but different transition curvatures. In both the measurements and calculations, the track edge noise increased more at high linear density with the head with larger transition curvature, due to its wider erase band, which was considered to be noise source at the track edge. We also clarified that reducing the transition curvature was effective to increase signal-to-noise ratio (SNR), especially at high linear density, and that reducing the track edge fluctuation was effective to increase SNR, especially at low linear density. Therefore, reducing both the transition curvature and track edge fluctuation is necessary to reduce track edge noise and consequently achieve high areal density.
\end{abstract}

Key words: magnetic recording, recording head, medium noise, transition curvature, track edge noise

\section{狭トラック記録再生における転移湾曲の信号品質へ与える影響}

椎本正人・片田裕之・浦上洋輔・橋本光弘・杉山幹人・市原貴幸・中本一広 日立製作所中央研究所，神奈川県小田原市国府津 2880 番地（广256-8510）

\section{1. はじめに}

ハードディスクドライブの高記録密度化のためには，線記録密 度およびトラック密度の向上が必要である. 線記録密度の向上に は，ビット境界における磁化転移ラインの摇らぎに起因する転移 性ジッタノイズ ${ }^{1)}$ の低減が必要であり, 記録へッドの磁界勾配の向 上，媒体の粒径や磁気クラスタの微細化やへッド - 軟磁性裏打ち 層間距離の低減などが有効である ${ }^{2)}$. トラック密度の向上には, 記 録および再生へッドの狭小化と，それに伴うへッド特性の低下を 抑制することが必要である。しかし，最近の検討により，記録へ ッドの磁界勾配が一定でも記録トラック幅が狭小化すると，トラ ックエッジノイズの影響が増加し，トラック中心においても SNR(Signal-to-Noise Ratio) が劣化することが明らかになっている ${ }^{3)}$ したがって, 高トラック密度化の実現には, トラックエッジノイ ズの低減が必須であり，その要因と物理を明らかにすることが重 要である.

トラックエッジノイズの要因の一つとして，トラック境界線の 摇らぎに起因するトラック端部の摇らぎノイズが知られている ${ }^{4,5}$ このトラック端部摇らぎを低減するためには，媒体の磁気クラス タサイズの低減 のや記録ヘッドのクロストラック方向の磁界勾配

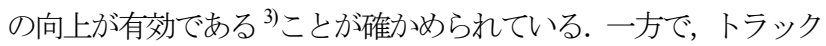
端部の磁化状態に着目寸ると, 記録転移線の湾曲 ${ }^{7,8)}$ もトラックエ ッジノイズに影響を与えていると考えられる，そこで，転移湾曲 がトラックエッジノイズに与える影響を明らかにすることを目的 として，記録磁界の湾曲量が異なるへッドを用いてトラックエッ ジノイズを検討した結果を報告する，また，転移湾曲とトラック 端部摇らぎが SNR に及ぼす影響がどのように異なるかについて も報告する.

\section{2. 実験及び計算方法}

\section{1 実測及び計算に用いたヘッド磁界分布計算方法}

実測及び計算に用いた記録へッドの磁界分布を有限要素

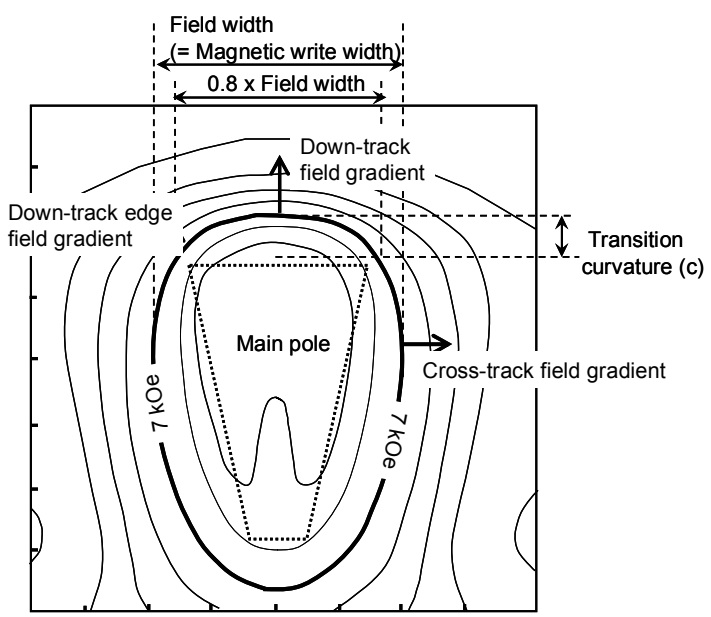

Fig. 1 Typical calculated head field contour. Field width, field gradient, and field curvature were defined as shown in this figure.

法 (FEM)により計算した。有効へッド磁界 $H_{\mathrm{eff}}$ は $H_{\text {eff }}=|H|\left(\cos \varphi^{1 / n}+\sin \varphi^{1 / n}\right)^{n}$ の式を用いて計算した.

ここで， $\varphi$ は媒体に垂直な面とヘッド磁界のなす角度であ る. 係数 $n$ は実測に用いた媒体の記録時の残留保磁力の角 度依存性と一致するように 1 とした。この条件における残 留保磁力の角度依存性は, 理想的な角度依存性を持つ Stoner-Wohlfarth model $(n=1.5)$ よりも小さく, 例えば $\varphi$ が 45 度のときの残留保磁力は $n=1.5$ の 1.4 倍になる. Fig. 1 に記録へッドの有効磁界分布の例を示す. Fig. 1 の磁界 幅は媒体の反転磁界である $7 \mathrm{kOe}$ における等磁界線のクロ ストラック方向への幅と定義した．また，磁界幅は実測の 磁気トラック幅(MWW) とほぼ一致することを確かめてい る。転移湾曲はトレーリング側から等磁界線（7 kOe $)$ ま での変異量と定義した，本研究では記録磁界の湾曲の大き さ(c)とクロストラック磁界勾配は，それぞれ磁界幅の $80 \%$ 
Table 1. Magnetic write width (MWW), transition curvature (c/MWW) of head field distribution, and effective transition curvature (ceff/MWW) for Head A, B, $\mathrm{C}$, and D.

\begin{tabular}{|c|c|c|c|}
\hline & $\begin{array}{c}\text { MWW } \\
\text { at } 235 \mathrm{kfci}\end{array}$ & $\begin{array}{c}\text { c/MWW } \\
\text { (FEM-cal.) }\end{array}$ & $\begin{array}{c}\mathrm{c}_{\text {eff }} / \mathrm{MWW} \\
\text { (fitting.) }\end{array}$ \\
\hline Head A (Meas.) & $88 \mathrm{~nm}$ & 0.13 & 0.48 \\
\hline Head B (Meas.) & $83 \mathrm{~nm}$ & 0.11 & 0.37 \\
\hline Head C (Cal.) & $72 \mathrm{~nm}$ & 0.12 & 0.44 \\
\hline Head D (Cal.) & $70 \mathrm{~nm}$ & 0.09 & 0.28 \\
\hline
\end{tabular}

の位置における等磁界線のダウントラック方向の位相の変 位量およびクロストラック方向の磁界勾配と定義した。

\section{2 評価方法および評価ヘッド}

本検討では，磁気トラック幅(MWW）がほぼ等しく転移 湾曲（c）が異なる 2 種類の記録へッド（Head A, B）のト ラックエッジノイズとイレーズバンド幅 (EBW)を評価し た ${ }^{9}$. Table 1 にHead A と B の 235 kfciにおける MWW, 記録磁化の実効的な規格化転移湾曲( $\left.\mathrm{ceff}_{\mathrm{eff}} / \mathrm{MWW}\right)$, および磁 界計算から求めた規格化転移湾曲 (c/MWW)を示す. $c_{\text {eff }}$ は, X. Che 等により提案されている MWW の線記録密度依存 性から算出する方法 10)を用いた。本検討では磁化転移形状 を楕円関数で表現し, 楕円の長径が MWWであり, 半短径 が実効的な転移湾曲 ( ceff) である仮定とした。また, 磁化転 移幅はクロストラック方向に一定であるとした。このよう に磁化転移形状を仮定することにより，MWWの線記録密 度依存性を計算することができ，これと実測による MWW の線記録密度依存性を比較することによって c eff が求めら れる. c eff / MWW は磁界の規格化転移湾曲より 3 倍程度大 きいが，定性的には磁界の規格化転移湾曲と相関がある. つまり, ヘッド磁界の転移湾曲が大きいヘッドを用いて記 録すると, 記録磁化の転移湾曲も大きくなることが確かめ られる，なお，実効的な記録磁化の転移湾曲が磁界の転移 湾曲より大きい理由は, 現実には磁化転移幅がトラック端 部において増大している影響が本手法では考慮されていな いためである.

再生ヘッドは磁気再生幅 (MRW) が $31 \mathrm{~nm}$ と MWWに 対して十分に狭いものを用いた。 また, 記録へッドの構造 による差だけを議論できるように，異なる記録へッドで記 録した信号を常に同一の再生へッドで再生した。媒体はキ ヤップ媒体 11)を用いた. ヘッドと媒体の記録層間の距離は $10 \mathrm{~nm}$ である.

\section{3 記録再生計算方法}

Landau-Lifshitz-Gilbert 方程式を用いたマイクロマグ ネティック計算 ${ }^{12)}$ を行い, 転移湾曲の異なるへッド (Head C, D）のトラックエッジノイズおよび SNR を検討した.
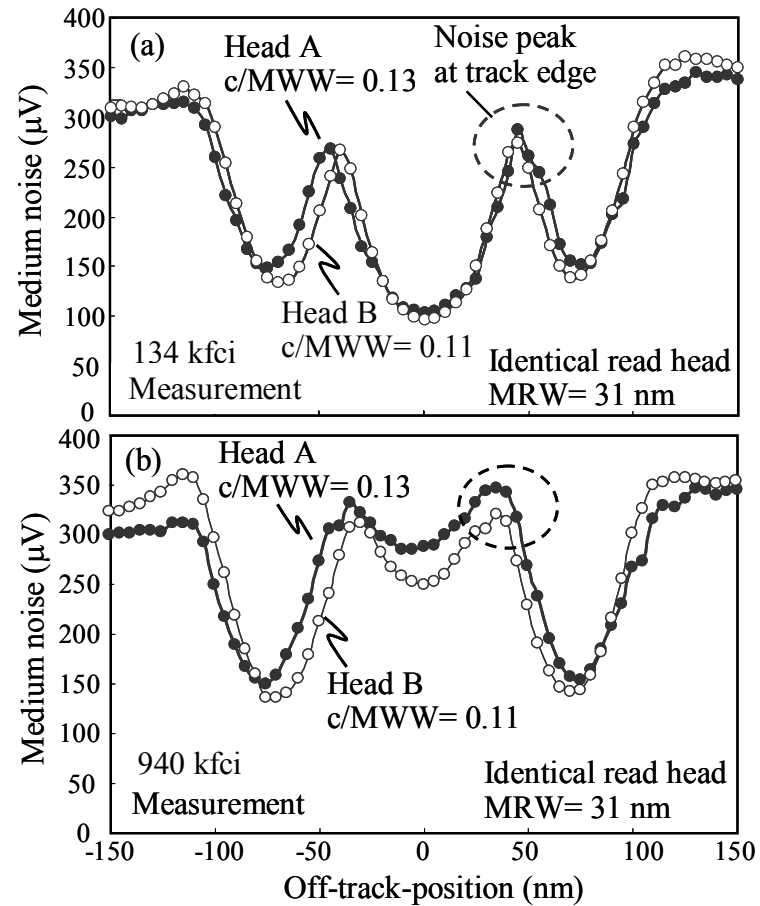

Fig. 2 Measured medium noise profile for Heads A and $\mathrm{B}$ at 134 and $940 \mathrm{kfci}$.

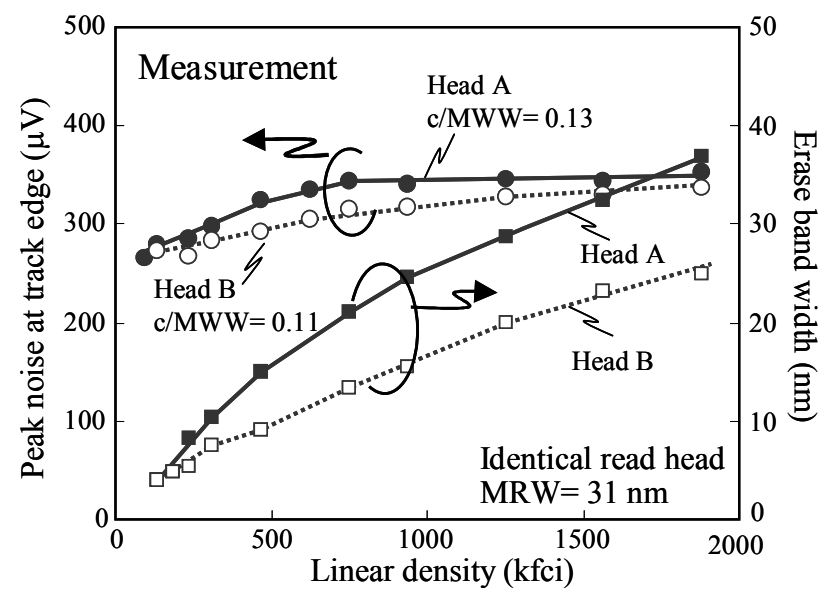

Fig. 3 Dependence of measured peak noise at track edge and erase band width on linear density for Head A and B.

\section{3. 実験・計算結果および考察}

\section{1 実測による転移湾曲がトラックエッジノイズに与える 影響の検討}

Fig. 2 に転移湾曲が異なるへッドの線記録密度が $134 \mathrm{kfci}$ および $940 \mathrm{kfci}$ におけるオフトラックノイズプロファイ ルの実測值を示す. トラック端部におけるノイズのピーク 值に着目すると, $134 \mathrm{kfci}$ では Head A と B ではほぼ等し いのに対し, 940 kfci では転移湾曲が大きい Head A の方 が Head Bよりも大きいことが分かる. Fig. 3 に，このト ラック端部におけるノイズのピーク值と EBW の線記録密 度依存性を示す．低線記録密度におけるノイズのピーク值 は Head A と B でほぼ等しいが，線記録密度が増加すると 転移湾曲が大きい Head A の方が大きくなる. EBW の線記 


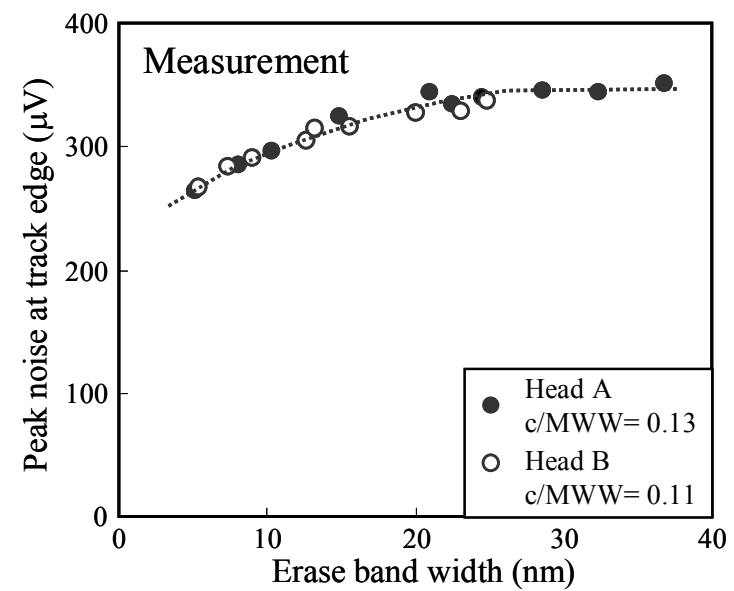

Fig. 4 Relationship between peak noise at track edge and erase band width for Head A and B.

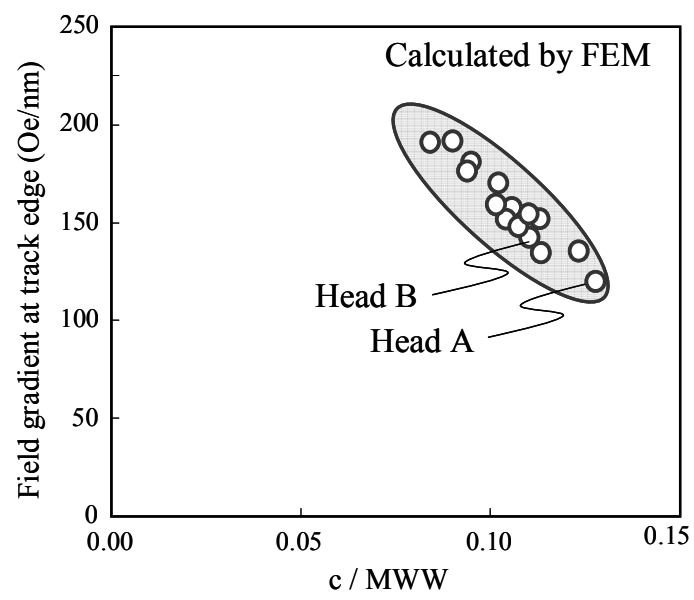

Fig. 5 Calculated field gradient at track edge vs. c/MWW.

録密度依存性もノイズピークの線記録密度依存性と同様に, 線記録密度が低いときには転移湾曲の大きさに依らず等し いが，線記録密度が増加すると転移湾曲が大きい Head A の方が大きくなる. Fig. 4 に Head A と B のトラック端部 におけるノイズのピーク值と EBW の関係を示す. トラッ ク端部のノイズのピーク值は EBW と非常に強い相関があ り,イレーズバンドがトラックエッジノイズと密接に関係 していることを示唆している.

\section{2 数値計算による転移湾曲がトラックエッジノイズ} に与える影響の検討

転移湾曲がイレーズバンドやトラックエッジノイズにどの ような影響を与えているのかを詳細に解析するために，数 值計算を行った。初めに, 転移湾曲によって高線記録密度 における EBW が異なる原因について解析する. Fig. 5 に 規格化転移湾曲とトラック端部における磁界勾配の関係を 有限要素法により求めた結果を示す。ここで，規格化転移 湾曲はヘッド構造を変化させることによって変化させてい る．転移湾曲が大きいヘッドはトラック端部における磁界 勾配の劣化が激しいことが分かる。この結果は，一般的に (a) Small transition curvature

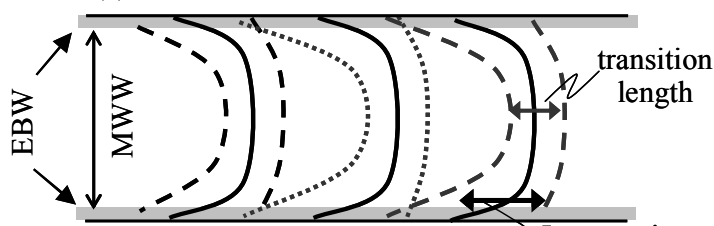

(b) Large transition curvature

Increase in transition

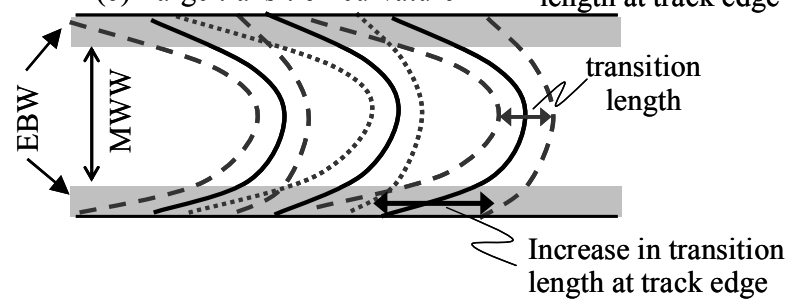

Fig. 6 Schematic images of recording pattern with different transition curvatures at high linear density.
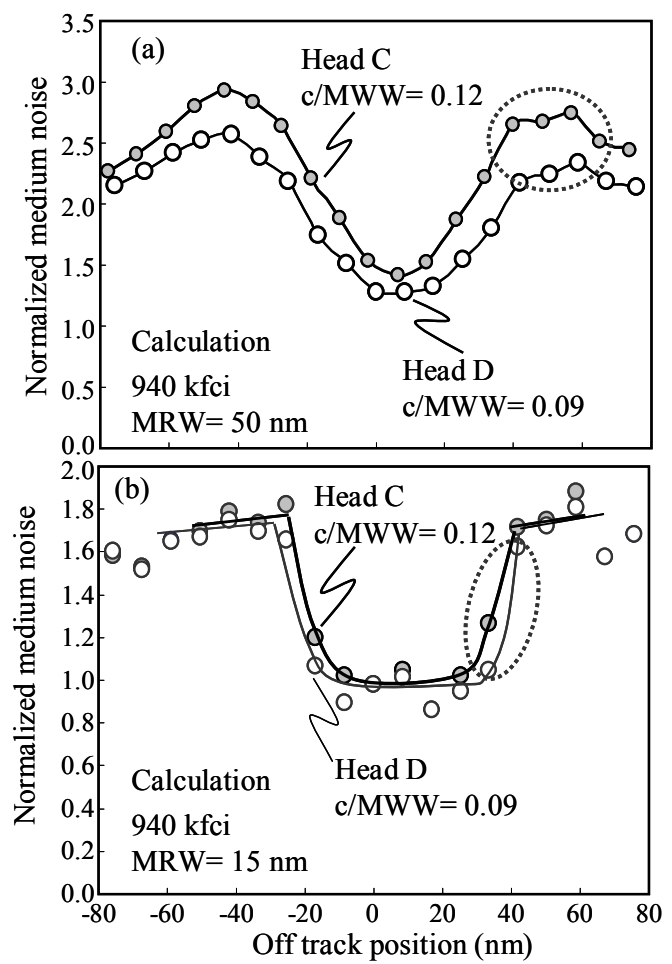

Fig. 7 Calculated normalized magnetic noise profiles for Heads $\mathrm{C}$ and $\mathrm{D}$ with different transition curvatures by using (a) wide-width read head and (b) narrow-width read head.

磁界勾配が低いほど磁化転移幅は増大寸るので，転移湾曲 が大きいヘッドではトラック端部における転移幅の広がり が大きいことを意味している．このような転移湾曲が異な る磁化状態の模式図を Fig. 6 に示寸. トラック端部におけ る転移幅が広く，また線記録密度が高いほど，トラック端 部におけるビット間の干渉が増大寸るので，信号が消失し た所謂イレーズバンド領域は増大すると考えられる。した がって，特に高線記録密度において転移湾曲の大きいいッ ドの $\mathrm{EBW}$ が大きい原因は，トラック端部の磁界勾配の劣 化に起因するトラック端部のビット干渉の増大によると考 

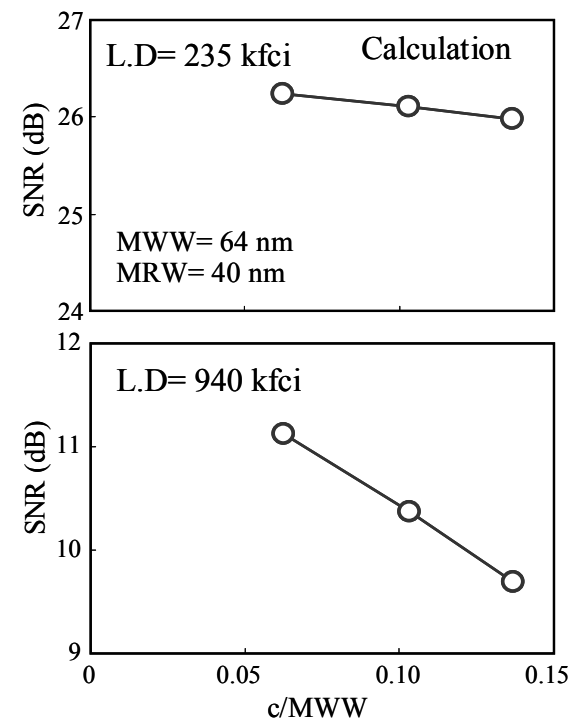

Fig. 8 Relationship between SNR at 235 and 940 kfci and normalized transition curvature.

えられる。また，イレーズバンド領域は波形の干渉により 擬似的に線記録密度が高くなった状態であるとすると, 非 常に高いノイズを持っていると考えることができる ${ }^{13)}$.こ のようなトラック端部における磁化状態とトラックエッジ ノイズの関係を明らかにするために，オフトラックノイズ プロファイルを計算した. Fig. 7 に，MWWがほぼ等しく 転移湾曲が異なる Head C と D の $940 \mathrm{kfci}$ におけるオフト ラックノイズプロファイルの計算結果を示す. 再生ヘッド は, MRW が $50 \mathrm{~nm}$ の比較的広いものと, $15 \mathrm{~nm}$ の非常に 狭いものの 2 種類を用いた. まず MRW が $50 \mathrm{~nm}$ のときの 結果を比較すると, 転移湾曲が大きいヘッドの方がトラッ ク端部のノイズのピーク值が大きく, 実測と似た振る舞い が確認できる. 次に, MRW が $15 \mathrm{~nm}$ のときのノイズプロ ファイルを比較する. トラック端部におけるノイズのピー ク值は転移湾曲に依らずほぼ等しいが，転移湾曲が大きい Head C の方がトラック端部のノイズがトラックの中央に 近づいていることが分かる.これは，Fig. 6 に示したよう に, 転移湾曲が大きいヘッドの方が, ノイズ源である EBW ${ }^{12)}$ が広いことに対応している. したがって, 転移湾曲 の増大に伴うトラックエッジノイズ増大は, ノイズ源であ るイレーズバンド領域の増大で説明できる.

\section{3 転移湾曲およびトラック端部摇らぎが SNR に与える影 響の検討}

転移湾曲及びトラック端部の摇らぎが SNR に与える影響 がどのように異なるのかを数值計算により検討した. Fig. 8 に, $235 \mathrm{kfci}$ および $940 \mathrm{kfci}$ における SNR と転移湾曲の 関係を示し, Fig. 9 にクロストラック方向の磁界勾配と SNR の関係を示す. クロストラック方向の磁界勾配は高い ほど，トラック端部の摇らぎに起因するトラックエッジノ イズが低減する。全ての条件において，235 kfciにおける
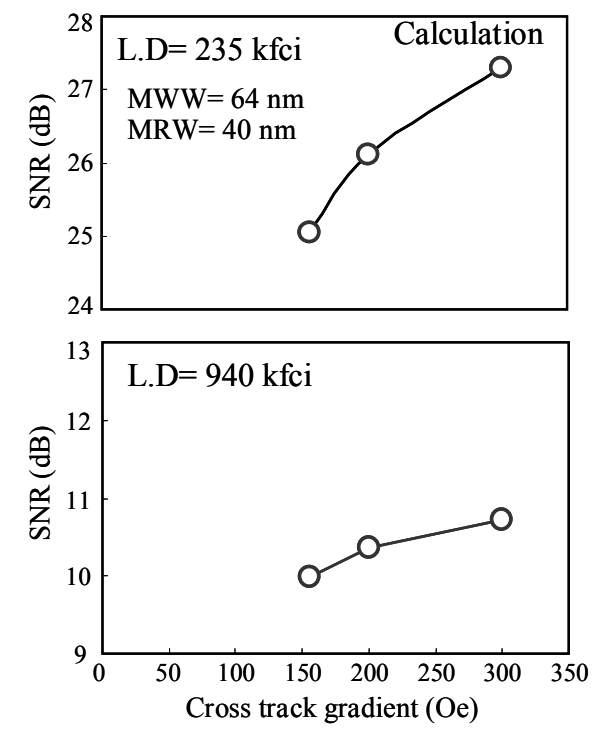

Fig. 9 Relationship between SNR at 235 and $940 \mathrm{kfci}$ and cross-track field gradient.

MWW は 64 nm であり, MRW は 40 nm である. Fig. 8 から転移湾曲の低減は, 比較的低記録密度である $235 \mathrm{kfci}$

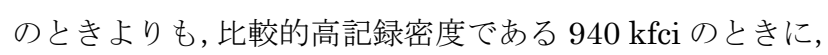
SNR の向上に有効であることが分かる．これは，転移湾曲 の低減による分解能向上効果に加え, 特に高記録密度にお いてトラックエッジノイズが低減する効果によるものであ る. 一方, クロストラック方向の磁界勾配の向上によるト ラック端部摇らぎノイズの低減は, Fig. 9 から高記録密度 よりも特に低記録密度において有効であることがわかる。 これは，トラック端部の摇らぎは線記録密度に依存しない ためであると考えられる。低記録密度のときには転移性ジ ッタノイズは小さいので，媒体ノイズ全体に占めるトラッ ク端部摇らぎによるノイズの割合が大きく，この低減によ る SNR の向上効果が大きい. 一方で, 高線記録密度のと きは転移性ジッタノイズが大きいので, 媒体ノイズに占め るトラック端部摇らぎの割合が小さく, この低減による $\mathrm{SNR}$ 向上効果も小さくなる.

\section{4 まとめ}

転移湾曲およびトラック端部の摇らぎが信号品質に与え る影響を明らかにするために，転移湾曲およびクロストラ ック方向への磁界勾配が異なるヘッドを実測と数值計算に より評価した結果，(1)転移湾曲が大きいヘッドの方が特に 線記録密度が高いときにトラックエッジノイズが大きいこ と (2)これは転移湾曲が大きいいッドの方がトラック端部に おけるノイズ源であるイレーズバンド幅が大きく，トラッ ク端部ノイズがトラック中心に近づくためであること(3)転 移湾曲の低減は主に高線記録密度における SNR の向上に 有効であり，トラック端部摇らぎの低減は主に低記録密度 SNRの向上に有効であること，の結論を得た。これらの結 論より, HDD の高記録密度化には, トラックエッジノイズ 
低減の観点から, 転移湾曲とトラック端部摇らぎの両方の

低減が必要であることが明らかになった。

謝辞 日立製作所の中川健氏，伊藤直人氏，松原正人氏， 西田靖孝氏, 渡邊克朗氏, 江藤久俊氏, 高澤浩幸氏, 日立 グローバルストレージテクノロジーズの石井生氏., 岡田行 正氏, 井手浩氏には本研究を行うにあたり多大のご協力を 頂きました。 ご協力頂いた方々に深く感謝致します.

\section{References}

1) K. Miura, H. Muraoka, Y. Sugita, and Y. Nakamura: J. Magn. Soc. Jpn., 24, 231 (2000).

2) K. Miura, H. Muraoka, and Y. Nakamura: IEEE Trans. Magn., 37, 1926 (2001).

3) Y. Urakami, N. Ito, H. Katada, M. Shiimoto, S. Das, M. Hashimoto, M. Sugiyama, and K. Nakamoto: IEEE. Trans. Magn., 45, 3656 (2009).

4) T. T. Lam, J. G. Zhu: IEEE Trans. Magn., 30, 4245 (1994).

5) T. Korenari, S. Tsuboi, T. Okumura, H. Matsutera, and K. Tagami: IEEE Trans. Magn., 33, 2509 (1997).

6) D. Sudo, M. Hashimoto, K. Miura, H. Muraoka, H. Aoi, and Y. Nakamura: J. Magn. Soc. Jpn., 30, 122 (2006).

7) M. Hashimoto, M. Salo, Y. Ikeda, A. Moser, R. Wood, and H. Muraoka: IEEE Trans. Magn., 43, 3315 (2007).

8) Hazel A. Shute, John C. Mallinson, and David T. Wilton: IEEE Trans. Magn., 43, 2025 (2007).

9) T. Kiya, K. Yamakawa, N. Honda, and K. Ouchi; J. Magn. Soc. Jpn., 33, 369 (2009)

10) X. Che, and N. Kim: IEEE. Trans. Magn., 42, 2300 (2006).

11) S. Das and H. Suzuki: J.Appl. Phys. 103, 07F540 (2008).

12) M. Igarashi, M. Hara, A. Nakamura, and Y. Sugita: IEEE. Trans. Magn., 39, 1897 (2003).

13) K. Miura, T. Ogawa, H. Aoi, H. Muraoka, and Y. Nakamura: J. Magn. Magn. Mater., 320, 2908 (2008).

2009年10月20日受理，2009年12月1日再受理，2010年3月17日採録 